\title{
Impasses da urbanização e regularização fundiária. Quem tem o poder de veto?
}

\author{
Urbanization and land regularization impasses. \\ Who has veto power?
}

Jeferson Tavares [I]

Marcel Fantin [II]

Douglas de Almeida Silva [III

\section{Resumo}

O objetivo deste artigo é problematizar os impasses nas decisões sobre remoções e regularização fundiária a partir do papel das ações de planejamento urbano em assentamentos precários. A questão central é compreender os conflitos interescalares e os embates entre os modelos de desenvolvimento urbano e ambiental. Nosso objeto de estudo é o processo de remoção dos moradores do jardim Nova Esperança, em São José dos Campos-SP sob dupla perspectiva: o empreendedorismo municipal e o plano de urbanização e regularização fundiária como instrumento de negociação. Os impasses que resultam desses conflitos são analisados pela teoria dos atores com poder de veto, particularizando a tomada de decisão sobre o uso e a propriedade da terra diante das novas formas de ordenamento territorial.

Palavras-chave: planejamento; remoções; plano de urbanização; regularização fundiária; atores com poder de veto.

\begin{abstract}
The objective of this article is to problematize impasses in decisions about removals and land regularization based on the role of urban planning actions in precarious settlements. The central issue is to understand the inter-scalar conflicts and clashes between the models of urban and environmental development. Our object of study is the removal process of residents from the Jardim Nova Esperança settlement, in the city of São José dos Campos, State of São Paulo, under a double perspective: municipal entrepreneurship and the urbanization and land regularization plan as a negotiation instrument. The impasses that result from these conflicts are analyzed through the veto player theory, particularizing decision-making about land use and land ownership in view of new forms of territorial planning.
\end{abstract}

Keywords: planning; removals; urbanization plan; land regularization; veto players. 


\section{Introdução}

As ações no campo do planejamento urbano e do urbanismo estão deslocando-se com maior intensidade da burocracia administrativa estatal para a iniciativa popular. Um conjunto de mudanças no papel da gestão e dos agentes públicos e privados tem contribuído para algumas iniciativas populares que procuram construir caminhos para o acesso aos serviços que o Estado não consegue prover e para a demanda que o mercado não tem interesse em atender. Esse movimento reposiciona o papel do planejamento no contexto atual.

Tal fato não é novidade. Em texto clássico, Oliveira (1981) demonstrou como a iniciativa da população marginalizada do processo legal de urbanização das grandes metrópoles construiu as periferias das cidades brasileiras por meio de iniciativa própria e desvinculada da administração pública e do mercado formal.

Nessa perspectiva histórica, podemos avaliar que a novidade das iniciativas populares contemporâneas encontra sua finalidade de reivindicação da cidade usando como instrumento o planejamento urbano. Pela natureza dos conflitos, muitas dessas iniciativas concentram-se na luta pela moradia como um ambiente mais amplo de luta por direitos econômicos, sociais e culturais, tendo na questão da localização um elemento central para efetivação dos direitos a saúde, educação (em todos os níveis) e lazer, assim como de condições de trabalho justas e favoráveis. Esse quadro de efetivação de direitos é completado pela segurança da posse da terra como componente central do direito à moradia adequada e pelo acesso aos serviços de saneamento básico e mobilidade. Portanto, essas iniciativas populares não se resumem à construção de unidades habitacionais, mas ao ordenamento urbano pela garantia de permanência na cidade e acesso à urbanidade.

Essas iniciativas populares ocorrem não exclusivamente pela autoconstrução, mas pela interferência no planejamento urbano e nas políticas públicas por meio de ações planejadoras, dentre elas os planos e projetos de urbanização, regularização fundiária, zoneamento, etc., que são discutidos e/ou formulados fora da administração pública e propostos a ela como alternativa à visão setorial e classista muitas vezes predominante. Na visão de Laval (2018), são essas iniciativas que guardam algum tipo de oportunidade para superar a nova razão do mundo em que o neoliberalismo leva "à degradação social e econômica da posição dos dominados, resultantes da lógica ao mesmo tempo competitiva e desigual do capitalismo neoliberal; a degradação acelerada do meio ambiente; e a degradação da via política democrática" (ibid., p. 164).

0 tradicional processo de planejamento urbano estatal, localizado no ambiente tecnocrático ou formulado em períodos de abertura democrática, sempre ocorreu de forma centralizada e sob sua exclusiva tutela. 0 que tem ocorrido nas últimas décadas, fundamentalmente após o processo de redemocratização, é a insurgência ou emergência de questionamento em relação a essa forma de planejamento, não exatamente aos seus instrumentos, mas ao processo a partir do qual é praticado.

O ponto de tensão é que, embora de iniciativa popular centrada na escala comunitária, a efetivação dessas ações depende das instituições (administrativas ou jurídicas) para sua implantação. 0 que leva a um impasse e à necessidade de negociação num campo 
eminentemente de conflitos e polarizações, tendo em vista que essas propostas são construídas muitas vezes em oposição às práticas tradicionais do planejamento.

Estão presentes, nesse processo, a administração pública (federal, estadual e municipal), o Poder Judiciário, o Ministério Público, a Defensoria Pública, as instituições de ensino (universidades), além de representantes de classe (entidades de classe profissionais, sindicais). Colaboram para esses embates os organismos de caráter multilateral, organizações sociais não governamentais (como associações comunitárias, de bairro, etc.) e a iniciativa privada a partir de setores econômicos tradicionais, como o mercado imobiliário, bancos, o setor industrial, de entretenimento, os veículos de imprensa (mídia televisiva e jornais impressos) e os escritórios técnicos (de engenharia consultiva e de planejamento urbano). Portanto, não se pode afirmar que o Estado não esteja presente nesse processo, mas a origem das demandas e decisões já não é mais centralizada e unidirecional.

As abordagens das intervenções passam pela ordem do espaço regional, metropolitano, local e de bairro, onde surgem diferentes iniciativas que, por um lado, formulam e aplicam os discursos ideológicos (Villaça, 2001); e, por outro, constituem resistências a esse projeto por proposições contra-hegemônicas. 0 que se apresenta é uma relação complexa de diferentes escalas institucionais e dimensionais que se cruzam num conflito pelo ordenamento do espaço urbano e que resultam em impasses decisórios que afetam populações vulneráveis.

A Comunidade do Jardim Nova Esperança, localizada no município de São José dos Campos-SP, apresenta elementos desses conflitos que permitem compreender essa problemática e formular questões e ponderações sobre os impasses e sobre as oportunidades de soluções. 0 que se propõe é a problematização desses conflitos a partir da área de conhecimento do planejamento urbano, buscando construir um pensamento sobre as alternativas possíveis.

\section{Empreendedorismo urbano e suas repercussões na cidade}

Empreendedorismo urbano, termo cunhado por Harvey (2005), é uma interpretação das novas maneiras de ordenamento urbano que surgem em fins dos anos 1980 nos países de capitalismo avançado, como meio de as cidades superarem a crise da década anterior pelas ações estratégicas de geração de renda provenientes do capital privado.

O modelo de empreendedorismo é contraposto ao tradicional modelo de administração dos recursos e configura-se por um novo papel da gestão estatal. Nele, a cidade é colocada como produto e condição dos processos sociais de transformação moldados pela lógica da circulação e acumulação do capital (ibid., p. 163). Essa postura empreendedora foi adotada como instrumento de desenvolvimento econômico envolvendo-se nas atividades de mercado, de produção e investimento. No empreendedorismo urbano, a competitividade e a busca pelo crescimento econômico locais ocorrem com certa autonomia do poder nacional, tendo em vista o anacronismo do regime fordista-keynesiano ante um regime de acumulação flexível (ibid., pp. 165-167) por meio de vantagens locacionais, negociações diretas com empresariado, competição de subsídios, etc. 
As estratégias ocorrem, de forma geral, pelos investimentos públicos que criam um contexto favorável para o investimento do capital privado; pela criação de condições competitivas do meio urbano para ampliar a participação na divisão espacial do consumo por meio de decisões, obras e eventos que construam uma imagem de cidade segura e inovadora; pela garantia de concentração de atividades de controle e comando que, por sua vez, requerem altos investimentos em infraestrutura e mão de obra qualificada; pela divisão do superávit por parte do governo central para abastecer ações dos governos locais; e, complementarmente, tem influência o papel da cidade na hierarquia urbana, por isso levam-se em conta as diferentes escalas espaciais para sua compreensão (zonas e comunidades locais, centros de cidade e subúrbios, região metropolitana e Estado-Nação) (ibid., pp. 169-176).

As ações praticadas pela prefeitura municipal de São José dos Campos e que, em última instância, repercutem nos esforços de remoção da Comunidade Jardim Nova Esperança resultam desse modelo de empreendedorismo que se apoia não apenas nas instâncias locais, mas também nas regionais e metropolitanas, porque correspondem às diferentes escalas institucionais desse tipo de ação.

\section{Algumas dimensões dos conflitos}

A relação de interescalaridade institucional e dimensional dos conflitos é uma particularidade no caso do jardim Nova Esperança. Aqui, trata-se especificamente como, nas escalas regional, metropolitana, local e de bairro, sobrepõem-se ações de abrangência internacional (por meio do BID), nacional (por meio da Petrobras e dos programas federais de provisão habitacional), estadual (pelas diferentes instâncias do governo do estado de São Paulo) e municipal (por meio da prefeitura de São José dos Campos e da associação de moradores do jardim Nova Esperança). Essa sobreposição cria uma rede de relações que é tensionada pela polarização entre a remoção ou a permanência dos moradores na região do Banhado, da qual emerge a necessidade de negociação entre poder público e iniciativa popular. E sobre a qual pesa o poder de decisão pela saída negociada ou pela remoção forçada.

Na escala regional e metropolitana: competitividade e segregação

A Região Metropolitana do Vale do Paraíba e Litoral Norte, cuja sede é o município de São José dos Campos, tem papel estratégico na potencialização da competitividade econômica da Macrometrópole Paulista. No PAM, Plano de Ação da Macrometrópole Paulista (Emplasa, 2014), estão previstas grandes obras logísticas com fins à integração territorial e ao posicionamento da macrometrópole numa divisão internacional do trabalho, por meio de atração de grandes investimentos empresariais. $\mathrm{E}$ a Região Metropolitana do Vale do Paraíba e Litoral Norte colabora nesse contexto por ser o principal eixo nacional de industrialização conectando diretamente a Região Metropolitana do Rio de Janeiro às regiões metropolitanas de São Paulo e de Campinas. No âmbito metropolitano, São José dos Campos tem incentivado e proporcionado um crescimento urbano 
espraiado, colaborando com a dispersão urbana por meio da extensiva implantação de condomínios residenciais fechados e dos recentes condomínios tecnológicos e industriais. No setor oeste, concentra-se a aprovação de condomínios residenciais de alto padrão que permitirão um processo de conurbação com projetos similares a serem implantados no município de Jacareí a partir do prolongamento da via Jaguari.

Lencioni (2008) traz o conceito de ilhas urbanas para tratar desse fenômeno, segundo o qual um "arquipélago" de condomínios residenciais fechados, shopping centers e outros enclaves fortificados, com poucas relações entre si, contribui para uma metrópole fragmentada e espraiada. Para a consolidação desse modelo, que contrapõe o conceito centro-periferia, principal compreensão do crescimento das cidades brasileiras durante o século $X X, 0$ acesso a uma autovia e às infraestruturas avançadas de telecomunicações é elemento fundamental a ser disponibilizado.

Essa estratégia reforça um padrão segregacionista ao se contrapor à predominância de construção de conjuntos habitacionais de baixa renda na porção leste do município, nas proximidades do município de Caçapava. Nessa escala, existe uma lógica clara de desenvolvimento liderada pelo município-sede (São José dos Campos) que setoriza porções da região pela constituição de áreas com maior ou menor potencial de desenvolvimento econômico, a partir das concentrações de classes sociais orientadas por polos de riqueza, no setor oeste, e de pobreza, no setor leste.

A articulação dessa estratégia regional e metropolitana passa por grandes obras setoriais, principalmente de transportes, que se estruturam pela Via Banhado. Essa Via, uma proposta de alça viária no centro da cidade para desviar o tráfego da área central, superar a barreira da rodovia Dutra e ligar os setores norte e oeste ao setor sudoeste, é o fato que materializa o conflito provocado pela prática do empreendedorismo urbano nas suas diferentes escalas e que impõe a agenda das remoções para o jardim Nova Esperança.

Na escala municipal:

sistema viário e remoções

O município de São José dos Campos tem longa história de concretização de seus planos diretores, fundamentalmente pela previsão de remoção de população pobre para promover a extensão do seu sistema viário.

No período de 1958 a 1964, foram propostos pelo Cepeu (Centro de Pesquisa e Estudos Urbanísticos), da Faculdade de Arquitetura e Urbanismo da Universidade de São Paulo, 21 projetos divididos em Plano Preliminar e Planos Setoriais. Nesse período, o Cepeu consolidou a estratégia da administração municipal de um planejamento urbano baseado na expansão do sistema viário municipal que se propagaria pelas áreas de fundos de vale e estaria interligado às rodovias estaduais (São José dos Campos, 1961). O segundo plano diretor, elaborado entre os anos de 1969 a 1971, pela Serete Engenharia S/A, Jorge Wilheim Arquitetos Associados e SD Consultoria de Planejamento Ltda. (Costa, 2007), propôs um anel viário como a "espinha dorsal" do município (São José dos Campos, 1971, p. 36). Em 1975, o município concluiu a ampliação da avenida Fundo de Vale, prevista pelos planos do Cepeu, e parte do anel viário, previsto pelo plano do consórcio de consultores (Amaral, 2008; Rosa Filho, 
2002), resultando na remoção de 150 famílias da Favela da Linha Velha e na criação de uma frente para a expansão industrial e imobiliária.

Nesse período, a prefeitura previu a remoção das famílias do Banhado para empreender um parque temático com recursos do Grupo Disneyworld (Almeida Silva; Vianna e Zanetti, 2017). A partir de 1996, intensificaram-se as remoções de comunidades de todo o município, que somaram 975 famílias (de onze núcleos) destinadas para conjuntos habitacionais, em média $16 \mathrm{~km}$ distantes dos locais de origem (Santos, 2010; Reschilian e Santos, 2014), com suporte do programa federal Habitar Brasil-BID, da ação estadual por meio da Companhia de Desenvolvimento Habitacional e Urbano (CDHU) e, mais recentemente, pelo programa federal Minha Casa Minha Vida.

0 maior expoente desse processo foi a ação sobre a comunidade do Pinheirinho, em 2012, que envolveu a remoção violenta de cerca de 1.500 famílias. A reintegração de posse da propriedade de Naji Robert Nahas onde, a partir de 2004, instalou-se a comunidade foi marcada pela liderança da prefeitura de São José dos Campos, subsidiada pelo judiciário (por meio de designação de um juiz estadual, assessor da Presidência do Tribunal de Justiça) e executada pela polícia militar (Souza, 2018, pp. 121 e 137), numa versão atualizada do modelo coronelista que articula poder público e privado por meio da força policial, para satisfação de uma classe social, como interpretou Leal (1948), no clássico Coronelismo, enxada e voto: o município e o regime representativo no Brasil.

Com as remoções, também ocorreu a ampliação do anel viário, incluindo os prolongamentos na marginal do ribeirão Vidoca, as vias Norte, Oeste e seu prolongamento, assim como as vias Cambuí e Jaguari (ambas em construção). Ainda estão previstas a Via Banhado e a ponte estaiada como finalização do anel viário (São José dos Campos, 2006).

Os curiosos casos do viaduto da Kanebo, cujas obras foram interrompidas pela crise dos anos 1980, e da projeção de uma ponte estaiada, denominada Arco de Inovação, simbolizam, na escala local, a substituição do modelo fordista de desenvolvimento pela hegemonia das recentes políticas neoliberais que têm como foco a valorização do Parque Tecnológico de São José dos Campos, cujo empreendimento destinado à promoção de ciência, tecnologia e inovação (fundado pela prefeitura em 2009) apresenta como expansão, para 2019, um bairro planejado, denominado Cidade Tecnológica, com espaço para setores residenciais, de serviços, moradias estudantis e da indústria denominada "4.0".

A inserção de novos atores no campo do planejamento urbano da cidade, nesse caso o Banco Interamericano de Desenvolvimento (BID), contribuiu consideravelmente para essa estratégia de novos empreendimentos, ao garantir linhas de crédito para a "desfavelização" e para investimentos viários a partir do Programa de Estruturação Urbana (PEU), celebrado em agosto de 2011, entre a prefeitura e o BID, por meio do contrato de empréstimo n. 2323 OC/BR (valor global de U\$178.026.200,00) que, dentre outras ações, prevê o reassentamento das famílias do jardim Nova Esperança para a construção da via no Banhado (BID, 2011).

Duas das poucas ações da prefeitura a se oporem à onda de remoções e reassentamentos foram: a aprovação da lei n. 144, de 22 de dezembro de 1994, que regulamentou as Zeis (Zonas Especiais de Interesse Social); 
e a formulação do Plano Diretor de 1995, realizado por meio de consultoria com Universidade Estadual Paulista (Unesp, campus de Rio Claro-SP), que definiu uma política habitacional com diretrizes voltadas às Zeis, à Habitação de Interesse Social (HIS) e à regularização fundiária e urbanística (Costa, 2007). Entretanto, a prefeitura não regulamentou a HIS, tampouco a regularização fundiária e urbanística dos loteamentos e assentamentos listados como Zeis, incluindo, nessa lista, o jardim Nova Esperança. A Lei de Zoneamento n. 428/2010, diante das disputas tensionadas pela sociedade civil, manteve a Zeis e foi incorporada nas bases do projeto de urbanização e regularização fundiária da comunidade, mas, na última regulamentação (lei complementar n. 623/2019), foi suprimida.

Na escala de bairro: o Banhado e a Comunidade Jardim Nova Esperança

Do ponto de vista ambiental, a área do Banhado é uma bacia sedimentar originária das formações geomorfológicas de Tremembé e São José dos Campos, integrante do sistema de várzeas do Rio Paraíba do Sul e caracterizada como um anfiteatro meândrico único em todo o Brasil (Ab'Saber, 1991). Constitui-se numa planície aluvial banhada, no passado, pelas cheias do rio Paraíba e separada do centro da cidade por uma falésia de aproximadamente $50 \mathrm{~m}$ de altura. É uma extensa área verde localizada no centro de São José dos Campos, e sua particularidade geomorfológica e topográfica proporciona uma vista privilegiada para a Serra da Mantiqueira, condições que fazem dela permanente objeto de valorização e especulação imobiliária.
De acordo com Morelli e Santos (1996), três elementos básicos definem a área: o rio, a várzea e a encosta semicircular. 0 processo de inundação acabou por constituir uma camada de sedimentos variados, incluindo terrenos com turfa, areia e argila, apresentando, também, terrenos férteis para o desenvolvimento da agricultura, o que, somado à construção do ramal da estrada de ferro na sua borda, no início do século XX, proporcionou atrativos para sua ocupação pela população pobre oriunda principalmente das zonas rurais. A área foi transformada em APA municipal (1984), APA estadual (2002) e Parque Municipal (2011), este último com recursos de compensações ambientais da Petrobras, como veremos a seguir.

O jardim Nova Esperança, uma comunidade de aproximadamente 460 famílias e cerca de 2.000 pessoas, está instalada há mais de 80 anos no Banhado. A comunidade é composta por dois núcleos habitacionais: o Núcleo I, área mais adensada que foi ocupada por trabalhadores rurais atraídos pelas ofertas de trabalho na indústria entre 1950 a 1980; e o Núcleo II que se caracteriza por uma área espraiada por chácaras e ocupada desde a década de 1930 por pequenos agricultores familiares (Alberini, 2015). Desde então, frente em face da ausência de políticas públicas inclusivas, a população que se destinou ao Banhado se consolidou no centro do município, beneficiada pela proximidade da infraestrutura e de serviços públicos urbanos, do emprego formal e dos consumidores para os produtos agrícolas ali cultivados. Essa população ocupa uma área aproximada de $255.000 \mathrm{~m}^{2}$, portanto de baixíssima densidade e com características predominantemente rurais (Figura 1 ). 
Figura 1 - Localização do município de São José dos Campos e da comunidade Jardim Nova Esperança
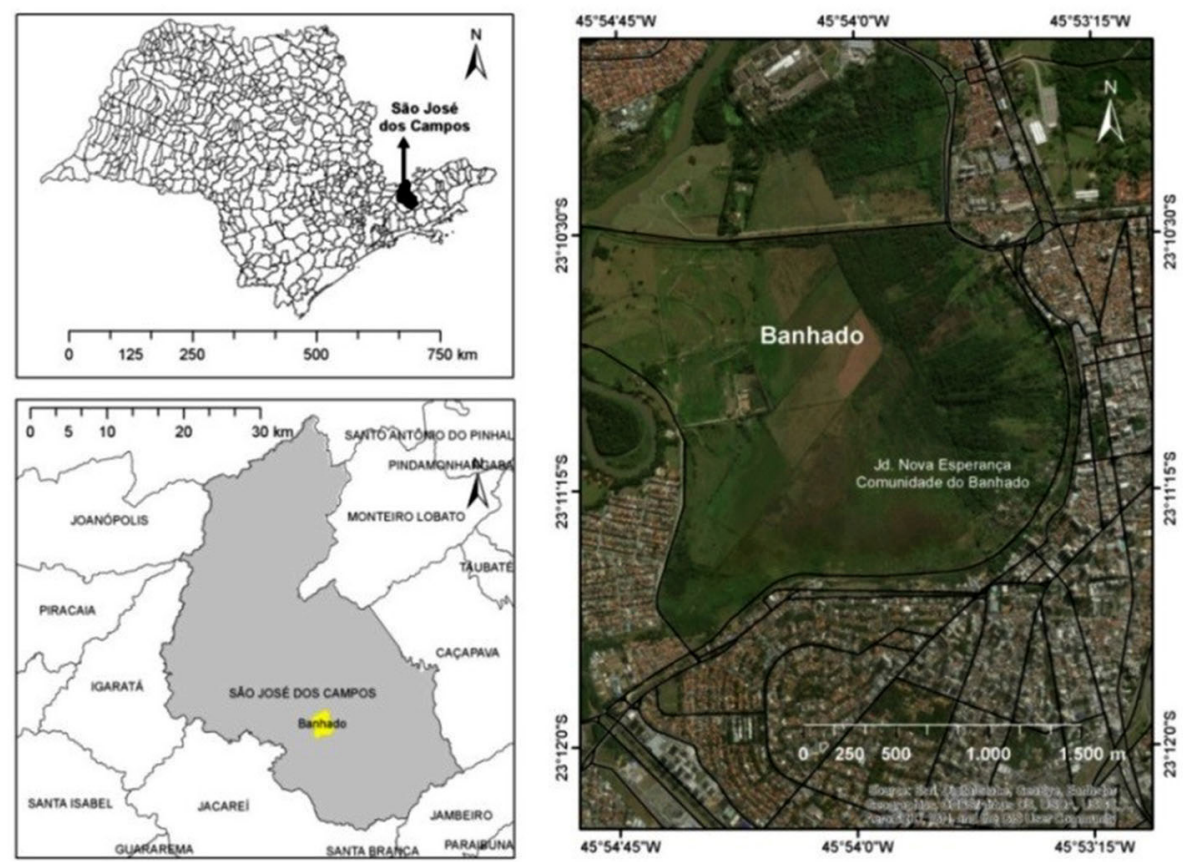

Fonte: Base Cartográfica do IBGE, de 2017 e Base Maps do Arcgis 10.1, de 2017.

As ações da prefeitura sobre a área, ao longo de décadas, ocorrem por uma sucessão de embates ambientais e sociais que têm resultado num lento, mas contínuo, processo de remoções dos moradores. As denúncias de repressões na comunidade por meio do controle sobre os moradores na entrada no bairro, vistorias, amparo às ações da prefeitura nas remoções e demolições sem a retirada do entulho são alguns dos exemplos da interpenetração do poder estatal nas suas escalas estadual e municipal, para o controle sobre um ambiente de constante vulnerabilidade social.
Essas ações hegemônicas e contra-hegemônicas compõem um mosaico de evidentes impasses que se desenvolvem a partir do conflito sobre a terra. A quem cabe a decisão final sobre esses impasses e a quem cabe a contestação da decisão ampliam a complexidade dos casos. Das novas formas de ordenamento territorial em que agentes nacionais e internacionais atuam pelos âmbitos municipal, estadual e federal, decorre um contexto a partir do qual o veto a um determinado pleito amplia os conflitos. 
O embate "ambiental versus social" construído para justificar as remoções

Como visto anteriormente, a tradição do planejamento urbano do município de São José dos Campos está baseada na circulação de ideias acerca de uma visão de ampliação do sistema viário, associado à atração de investimentos industriais, comerciais e imobiliários, que sustentou as propostas de transformação do espaço urbano.

A base dos conflitos entre o desenho neoliberal de cidade e as ações de resistência a esse projeto está no uso da terra, que se traduz em remoções de populações vulneráveis de áreas centrais e/ou de interesse do capital imobiliário para conjuntos habitacionais periféricos. Forçadas ou por adesão, essas remoções são essenciais na manutenção dessa estratégia de desenvolvimento urbano.

Assim, na falta de acordo, predomina um arcabouço legal construído especificamente para garantir a retirada dos moradores pobres com força policial. No caso específico da Comunidade Jardim Nova Esperança, os argumentos construídos buscam opor a questão ambiental à questão social, como se fosse possível dissociar ambas, a fim de proporcionar um desenvolvimento urbano dito sustentável que, contudo, resulta desigual. O Estudo de Impacto Ambiental da Via Banhado evidencia esse discurso ao minimizar os efeitos desestabilizadores desse projeto sobre a comunidade e o que dela resulta na produção agrícola, reposição e conservação da mata existente, considerando o comprometimento de relações culturais, sociais, incluindo as dinâmicas de trabalho e de produção como forte enraizamento territorial e, também, responsáveis pela subsistência direta dessa população.
A desproporcionalidade da correlação de forças em contextos dessa natureza é evidenciada quando as obras de infraestrutura, que apresentam consequências ambientalmente danosas em suas fases de implantação e operação, mas que estão integradas às carteiras preferenciais de projetos do poder público, acabam por prevalecer sobre preexistências não inseridas ou desimportantes para os circuitos de produção associados à agenda estatal. Assim, o debate da desigualdade coloca em questão que "não é simplesmente a sustentabilidade dos recursos e do meio ambiente, ou as escolhas técnicas deslocadas da dinâmica da sociedade, mas sim as formas sociais de apropriação, uso e mau uso desses recursos e desse ambiente" (Acserald, Mello e Bezerra, 2009, p. 76) que também importam e que, portanto, devem ser consideradas pelas esferas de decisão.

A armadilha de um posicionamento polarizado pelo ideário preservacionista, desconsiderando a realidade socioeconômica do histórico dos processos brasileiros de urbanização recai sobre soluções setoriais excludentes do ponto de vista social. $\mathrm{O}$ embate entre as questões ambientais (considerando o viés preservacionista do Banhado) e sociais (considerando a presença de uma comunidade na área) vem sendo explorado como argumento para o processo de remoção dessas famílias.

As primeiras ações ocorreram pela instituição de uma APA (Área de Proteção Ambiental), em 1984, pela lei municipal n. 2792/1984, que reforçou o caráter preservacionista das políticas públicas sobre o Banhado (São José dos Campos, 1984). Em 2002, ampliou-se sua abrangência institucional pela aprovação da lei estadual n. 11.262/2002, que instituiu a APA estadual do Banhado (Estado de São Paulo, 
2002). A APA do Banhado, inserida na zona urbana, não foi regulamentada até o momento, e a legislação que a instituiu apresenta restrições de caráter geral.

Em 2006, a prefeitura assinou um Termo de Compromisso de Compensação Ambiental (TCCA) junto à Revap - Refinaria Henrique Lage, da Petrobras, para compensação em função da ampliação da refinaria. Esse termo previa a contribuição de $\mathrm{R} \$ 10$ milhões da Petrobras para a prefeitura a serem divididos entre 0 Parque Natural Municipal Augusto Ruschi (R\$1 mi) e a criação do Parque Natural Municipal o Banhado (PNMB) (R\$ 9 mi) (São José dos Campos, 2010). Em 2012, o Poder Executivo enviou à Câmara Municipal de São José dos Campos o projeto de lei municipal n. 658/2011, que criava o PNMB, posteriormente sancionado pela lei municipal n. 8756/2012. Como a APA permite certo grau de ocupação humana e a existência de terrenos particulares, o parque é de posse e domínio público e cria restrições à permanência de moradores (Brasil, 2000). Dessa sobreposição ambígua de diretrizes ambientais, a prefeitura posicionou-se pela remoção da comunidade (Almeida Silva, 2017), mesmo diante do fato de o Banhado pertencer a diferentes proprietários particulares.

Uma vez criados os argumentos legais, mas sem efeitos práticos imediatos devido à resistência dos moradores, a prefeitura partiu para o isolamento da comunidade pela demolição dos equipamentos sociais existentes na área (o espaço para enfermaria e tratamento odontológico; a Emei; o Posto Policial; a FUNDHAS, Fundação Hélio Augusto de Souza, destinada a cursos técnicos de crianças e adultos; a creche, o campo de futebol e o posto de saúde) e pela proibição de serviços de saneamento, tendo em vista o caráter, então irregular, do assentamento. Ações que reforçaram o conflito e deixaram eminente a necessidade de uma aproximação entre as partes interessadas, gestão pública e comunidade.

No ano de 2008 foi instituído o Alvará Especial de Construção, através da lei complementar n. 373/2008, para controlar, por meio de autorização específica, a construção de residências unifamiliares nos loteamentos em processo de regularização, classificados como Zeis, desde que o núcleo tivesse lei autorizativa editada pela Câmara. E em 2015, por meio da lei n. 9.258/2015, a prefeitura instituiu o programa municipal de Compra Assistida para ser o instrumento legal de remoção das famílias, com o objetivo de viabilizar a implantação do parque e da via Banhado prevista sobre o platô onde se encontravam as residências da comunidade.

O Estudo de Impacto Ambiental (EIA) da Via Banhado, elaborado em 2013 pelo Consórcio Planservi-Cobrape, avaliou quatro alternativas geométricas de implantação, bem como uma alternativa referente à inviabilidade de sua não implantação. Primeiramente, o EIA apontou as consequências negativas para a alternativa de não construção da via. Das quatro alternativas, a indicada pelo relatório como preferencial (alternativa $\mathrm{C}$ ) incide sobre a comunidade, sendo necessária a remoção completa das moradias. Contudo, o relatório não mensurava esse impacto (São José dos Campos, 2013, p. 61). A carência ou ausência de integração das propostas com a comunidade foi concebida da seguinte forma: as alternativas de não construção da via e o cenário $B$ não mencionam a comunidade como elemento para a avaliação projetual (p. 60); as alternativas A, C (p. 61) e D (p. 61) consideram com importância mínima o impacto da via sobre a 
comunidade. Some-se a isso o fato de a viabilização da verba do BID para a construção da alça depender da transformação da área do Banhado em parque, para isso a criação da lei n. 8756/2012, já mencionada.

A reação ao ElA-Rima ocorreu por meio de um informativo, do dia 14 de setembro de 2014, distribuído pela Defensoria Pública do Estado. 0 órgão criticou a inexistência de participação popular nos planos e propostas para o Banhado. Na ocasião, a prefeitura municipal não havia discutido com a população o conteúdo do estudo técnico, o que levou a Defensoria a crer que a prefeitura tenha considerado a implantação da via como um "fato consumado", evitando qualquer tipo de consulta àqueles atingidos diretamente (Defensoria SP, Informativo, 2014). Complementarmente, em 2011, a Central de Movimentos Populares (CMP) enviou denúncia ao escritório do BID, denominado Mecanismo Independente de Consulta e Investigação (Mici), cuja função é fiscalizar os descumprimentos das políticas operacionais do Banco. A denúncia baseava-se nos prejuízos causados às comunidades vila Nova Tatetuba e jardim Nova Esperança pelos projetos financiados pelo BID. Após as investigações, a equipe concluiu que o BID descumpriu suas políticas operacionais destinadas a salvaguardar a comunidade do Banhado em questões habitacionais, ambientais e transparência na comunicação do projeto MEC (Mici, 2017, pp. 8-37).

No final de 2014 e início de 2015, os moradores receberam uma proposta da prefeitura para a desocupação da área em troca de unidades habitacionais no Residencial Jaguary, cerca de $15 \mathrm{~km}$ distante do Banhado, conjunto habitacional que integra um cinturão periférico que vem crescendo com programas habitacionais de baixa renda da CDHU e do programa Minha Casa Minha Vida, além de diversas autoconstruções em bairros clandestinos, em conjunto com uma infraestrutura viária que enfatiza a ocupação periférica e o crescimento horizontal.

Sem apoio do BID e com as dificuldades de investimento da CDHU em face da crise econômica recente, a prefeitura de São José dos Campos, através do programa Casa Joseense, criado por meio da lei complementar municipal n. 604/2018 e regulamentado pelo decreto municipal n. 17.769/2018, passou a oferecer aos moradores $\mathrm{R} \$ 5$ mil para auxílio demolição e mudança, bem como $R \$ 700,00$ mensais de auxílio aluguel por tempo indeterminado. As ações de divulgação com o lema "mudar faz bem" são sistemáticas e desenvolvidas através da distribuição de panfletos e carros de som.

Essa conjuntura institucional de pressão sobre a comunidade levou os moradores a se organizarem para construir uma resistência, tendo como momento simbólico o abraço ao centro comunitário, que impediu a sua demolição. Mais recentemente, a comunidade tomou a iniciativa, com a Defensoria, de propor um Plano Popular de Urbanização e Regularização Fundiária do jardim Nova Esperança.

\section{Plano de urbanização como instrumento de negociação}

A constatação de que o modelo fordista de produção e o modelo keynesiano de organização social e econômica do Estado-Nação passam por uma crise e são paulatinamente substituídos por outros modos produtivos implica a necessidade de revisão do tradicional modelo de planejamento urbano baseado na previsão de problemas e soluções, e que é 
conduzido de forma centralizada pelo Estado (Ascher, 2010, pp. 48-50). Esse contexto exige novas formas de viabilizar soluções para o espaço urbano, considerando suas novas demandas e o papel de novos atores nessa condução. Essas novas formas devem privilegiar os meios democráticos e de regulação mais reflexivos, de procedimentos mais capilarizados nas comunidades, deliberativos e solidários, com defesa do projeto em oposição aos programas, das "soluções ad hoc" ao invés das normas e de consensos parciais (ibid., pp. 61-79) que invariavelmente tendem aos setores e às classes sociais com maior poder de decisão.

As cidades, incluindo as suas porções mais pobres, organizam-se para além das formas mais tradicionais de regulação do espaço que, por sua vez, já não fazem mais sentido como faziam antes da evolução tecnológica, pois o lugar da edificação regulado por um zoneamento restritivo, muitas vezes monofuncional, não se aplica num contexto no qual a diversidade de usos tem um papel mais amplo, como nas porções urbanas em que as atividades informais ou mesmo de agricultura familiar se tornaram alternativa ao desemprego e não raras vezes a base das novas relações de trabalho adiante da flexibilização das leis trabalhistas.

É característica desse momento a elaboração de projetos num contexto incerto e de constantes transformações cada vez mais rápidas, e por isso o projeto torna-se instrumento de análise de negociação, buscando enfrentar os conflitos menos pelas decisões embasadas pelas maiorias - que são circunstanciais - e mais pelos compromissos que abordem e garantam a diversidade de interesses por uma pauta de governança mais ampla social e territorialmente (ibid., pp. 83-86).
No jardim Nova Esperança, a configuração de ambiente alternativo de novas propostas de ordenamento territorial ocorre de forma paulatina e se iniciou pelo reconhecimento das formas tradicionais de ocupação, pela identificação das memórias populares, pela valorização dos vínculos afetivos entre a população e o local e pela tentativa de preservação do patrimônio histórico-cultural dos costumes locais que se deram pela proposta de tombamento da paisagem urbana e natural empreendida por pesquisadores da Univap junto ao Conselho do Patrimônio Histórico, Arqueológico, Artístico e Turístico do Estado de São Paulo (Condephaat) (protocolo 6/5/2015). 0 pedido de tombamento valorizou o Banhado e as famílias que lá residem como patrimônio estadual e paisagem socioambiental do Vale do Paraíba pela representação de categorias de proteção imaterial e cultural. Do pedido de tombamento é possível apontar a importância da ocupação pela preservação dos modos de fazer e formas de expressão que denotam práticas culturais remotas, como danças, lendas, casas de pau a pique e ofícios rurais. Propôs a preservação dos patrimônios arqueológicos de significativo valor histórico-cultural, como o muro de arrimo em pedra seca com barbacãs construído pela Estação de Ferro Central do Brasil (EFCB), as nove casas de padrão operário relacionadas à arquitetura ferroviária, os fragmentos de louça de produção nacional depositados na superfície, entre outros patrimônios arquitetônicos. A proposta descontrói a imagem do Banhado como paisagem neutra ou de seu valor estar vinculado única e exclusivamente às questões ambientalmente preservacionistas, reinterpretando o Banhado também pelo valor social (Almeida Silva, 2015). 
Outra ação articulada com a comunidade foi a proposição da ação civil pública n. 1026895-69.2018.8.26.0577, através da Defensoria Pública do Estado de São Paulo, em 26 de novembro de 2018. Essa ação teve como objetivo requerer uma liminar contra o município de São José dos Campos com o intuito de exigir a retirada do entulho deixado pelas demolições e de inibir novos atos de assédio à comunidade após o bloqueio de uma via de acesso ao bairro, assim como de solicitar a regularização fundiária e urbanística do jardim Nova Esperança. A ação aponta para o descumprimento por parte do Executivo Municipal de tratados internacionais dos quais o País é signatário e para a violação à Constituição Federal, em especial ao direito à moradia e à concretização das políticas públicas de habitação social, saneamento básico e erradicação da pobreza e marginalização; e destaca a violação do direito à cidade, recuperando as diretrizes preconizadas pelo Estatuto da Cidade (artigo 2 으, inciso XIV da lei federal n. 10.257/2001) e pela lei federal n. 13.465/2017, e a violação do direito ao planejamento urbano (artigo 30, inciso VIII da Constituição Federal, que prevê que o município tem de promover o ordenamento territorial).

No mesmo ano, buscando atender a um pleito da Defensoria e da comunidade, de promover a regularização fundiária da área, uma equipe interdisciplinar fora do âmbito da burocracia administrativa iniciou a elaboração do Plano Popular de Urbanização e Regularização Fundiária do jardim Nova Esperança. O plano incorpora o conjunto de ações em defesa da comunidade e propõe uma resposta à prefeitura, buscando demonstrar a viabilidade de manter e regularizar a comunidade dentro da área do Banhado e os efeitos positivos que esse planejamento deve acarretar para a cidade de São José dos Campos e, em especial, para os elementos ambientais do Banhado, criando um contraponto sólido à proposta da prefeitura de remoção dos moradores. A elaboração do plano proporciona ferramentas de discussão e disputa com o poder público, construídas de maneira coletiva e igualitária. $A$ viabilidade de um plano de urbanização e de regularização fora do âmbito administrativo-burocrático estatal foi construída a partir de recursos vinculados aos chamamentos públicos de projetos sociais proporcionados pela Universidade de São Paulo (USP) e pelo Conselho Regional de Arquitetura e Urbanismo de São Paulo (CAU-SP), assim como pela integração das áreas de arquitetura e urbanismo (Instituto de Arquitetura e Urbanismo-USP), do direito (Faculdade de Direito de Ribeirão Preto-USP), da engenharia ambiental e civil (Escola de Engenharia de São Carlos-USP) e da área de planejamento urbano e regional da Universidade do Vale do Paraíba, com constante diálogo com a comunidade, a Defensoria Pública e organizações não governamentais.

Nesse aspecto, o processo de elaboração tem igual importância em relação ao seu produto final, pois se trata da reunião das ações e dos esforços anteriores e de mobilização social para a proposição de uma alternativa à proposta da prefeitura. Busca consolidar um espaço aberto e democrático de debates, sem deixar de incluir os órgãos administrativos, incorporando a visão dos distintos atores relevantes ao contexto social no desenvolvimento do plano, assim como a articulação entre os atores sociais relevantes ao contexto. A aplicação de novas tecnologias, como o uso de aeronave remotamente pilotada (RAP) e de softwares livres de planejamento urbano, possibilita 
levantamentos de alta precisão a baixo custo na construção de bases cartográficas, o que garante a apropriação técnica do território pela população. As novas ferramentas projetuais para o campo do urbanismo têm sido aplicadas para fins sociais como instrumentos tecnológicos para a conquista do direito à cidade. Seu uso ocorre pela sua inserção como ferramenta facilitadora de processos que promovam empoderamento espacial e identitário em assentamentos precários, considerando questões intrínsecas e especificidades de grupos sociais e seus contextos.

Especificamente no âmbito social, a elaboração do plano possibilita a consciência pela luta popular sobre as remoções forçadas, proporcionando oportunidades de discussão construídas de maneira coletiva e igualitária pelo modelo bottom-up, que possam ser propagadas, replicadas e transformadas em outras comunidades. Nem por isso descarta algumas das condições preexistentes e particulares da área, como a constituição do parque municipal e da necessidade de um arco viário intermodal para o desafogamento do tráfego da área central e uso pelo transporte público, contudo buscando convergência com os interesses comuns e não excludentes. Nesse aspecto, o plano urbanístico e de regularização fundiária é construído como um meio de negociação com a prefeitura, cujo fim tem vistas à permanência segura e adequada dos moradores.

Essas ações não resolveram, por si só, os conflitos instalados nem tiveram a pretensão de encerrar essas demandas. Mas, representaram uma alternativa a uma população na iminência de ações de remoções. Provisoriamente, contribuíram para o parecer judicial favorável à permanência da população (processo n. 1026895-69.2018.8.26.0577). Além do otimismo que a decisão tenha gerado, importante apontar que a regularização no uso e na posse da terra é mais complexo e extenso.

Considerando o aporte teórico de Matus (1996a), a importância de a comunidade estar organizada politicamente ao redor de um plano também se dá pela amplificação de seu peso coletivo dentro do jogo social, ao ser municiada com um arcabouço técnico e político. Considerando esse jogo social, o plano pode ser considerado um potencializador do poder político e do prestígio social da comunidade e servir como estratégia para atingir os objetivos propostos, pois permite acumular e melhorar as capacidades dialógicas derivadas da sua concepção coletiva. Matus (ibid., pp. 14-16) pondera que um ator deve explorar zonas intermediárias, lidando, por um lado, com a cooperação nebulosa e, por outro, com o confronto que pressupõe o reconhecimento explícito de interesses opostos. Quando há um jogo de forças no qual uma parte deve vencer a outra, vence a proposta que tem a capacidade de arregimentar afinidades e acumular poder político entre a ampla gama de atores envolvidos nessa disputa. No caso da adoção da estratégia de cooperação, procura-se atingir objetivos compatíveis ou comuns que sacrifiquem objetivos particulares. O problema aumenta em complexidade quando nenhum dos atores pode, em separado, atingir seus objetivos. Quando se trata de interesses distintos, mas conciliáveis, ocorre o intercâmbio de problemas, pesando-se a possibilidade de conquista total dos objetivos com pouca probabilidade de êxito e a conquista parcial com alta probabilidade de êxito. 0 que se coloca, nessa situação, é comparar o custo de negociar. É dentro dessa lógica que o plano popular de urbanização cumpre o seu papel. Ele disputa a agenda 
e a narrativa, mas, por si só, é pouco eficiente. Sendo assim, tão importante quanto a elaboração do plano é a estratégia política que se adota para concretizá-lo. Diante desse contexto, a pergunta que se coloca é: qual é a estratégia a ser adotada, considerando um gradiente de cooperação e conflito ao se relacionar com o poder de veto?

\section{Impasses e os atores com poder de veto}

Os diferentes níveis das escalas institucional e dimensional interpenetram-se, criando uma rede complexa de relações entre os agentes internacionais, nacionais e subnacionais que se concentram em tensões cujos efeitos afetam a comunidade. Essas relações parecem organizar-se pela polarização, substituindo os diálogos pelos embates. Essa polarização neutraliza qualquer possibilidade de um resultado ganha-ganha, conduzindo a um processo, em geral, violento, cujos resultados tendem às forças mais conservadoras.

Desse conflito, resultam impasses, um dos quais relacionado à tomada de decisão pela permanência ou não dos moradores na área. Nesse impasse, há que se considerar que essa decisão passa, de um lado, pelo desejo da população e, de outro pela concordância da prefeitura. Pela teoria dos atores com poder de veto (Tsebelis, 2009, p. 37), "[...] os resultados decisórios são consequência de dois fatores: das preferências dos atores envolvidos e das instituições dominantes". A partir da analogia entre (1) os princípios fundamentais da teoria dos atores com poder de veto e (2) o contexto no qual se insere a Comunidade do Jardim
Nova Esperança, podemos problematizar o impasse da polarização instaurada e indicar alternativas a esses impasses, tendo em vista que, diferentemente do planejamento tradicional (promovido pelo Estado e por ele praticado), atualmente temos um novo modo de construir ações planejadoras, feito fora das gestões administrativas, mas ainda dependente de suas instituições para sua concretização. A "teoria dos atores com poder de veto enfoca a atividade política legislativa e o modo como são tomadas as decisões sobre a elaboração de leis, visando explicar uma série de políticas de governo e outras características importantes da política" (ibid., p. 391). Portanto, o que aqui propomos é o empréstimo de alguns de seus conceitos e formulações, transpondo-os para o âmbito dos conflitos urbanos e, em especial, do planejamento por iniciativa popular como prática de ordenamento territorial.

Nesse contexto, importa compreender a mudança do status quo que está vinculada ao grau de estabilidade decisória que, por sua vez, depende dos membros envolvidos. A estabilidade decisória é mensurada pela dificuldade de mudança das condições vigentes (ibid., p. 64). E, no caso do Banhado, os membros envolvidos atuam de forma recíproca, distantes entre si na perspectiva de um acordo e dentro de um sistema de decisão que ocorre pelo âmbito individual e político-administrativo. Individual pela decisão do morador em aceitar ou não as propostas de reassentamento feitas pela prefeitura; e político-administrativo pela decisão da prefeitura de aplicar ou não o plano urbanístico e de regularização fundiária proposto pela comunidade. O status quo, nesse contexto, é caracterizado pela fragilidade de permanência dos moradores no Banhado e, portanto, do risco da perda de seus direitos. 
A rigor, a prefeitura detém poder sobre a decisão de remoção e reassentamento, contudo não o faz de imediato, tendo em vista o ônus político, os custos e os desgastes de uma decisão unilateral que remonta ao trágico caso do Pinheirinho.

A distância de posições entre os atores, conformada pelos antagonismos e polarizações, representa baixíssima perspectiva de acordo que pode resultar na postergação dos conflitos com consequências negativas a ambas as partes, não descartando os processos violentos recorrentes nesses contextos. Os impasses acima apresentados, entre a comunidade e a gestão pública, são representativos dos impasses que caracterizam as tomadas de decisão e, portanto, do aumento da estabilidade decisória. Quanto maior for a distância entre esses atores, mais difícil será a mudança do status quo (ibid., p. 41).

Nessas circunstâncias, cada um dos atores (a prefeitura e a comunidade) age simultaneamente como propositor de uma agenda (numa determinada ocasião) e como ator com poder de veto (em outra ocasião). A prefeitura atua como propositora de uma agenda, quando propõe a remoção dos moradores, cuja concretização depende do aceite ou do veto da comunidade (aqui representada por decisões familiares ou individuais). A comunidade atua como propositora de uma agenda quando propõe um plano de permanência (por meio de um plano urbanístico e de regularização fundiária), cuja concretização depende do aceite ou do veto da prefeitura. A agenda da prefeitura é mais frágil porque é mais lenta e pulverizada, já a agenda da comunidade é objetiva e requer pronto posicionamento da prefeitura. Nesse aspecto, o sucesso de uma solução aos conflitos, construída coletivamente, consolida-se pela concretização da agenda da comunidade mediante a aceitação pela prefeitura. Então, na hipótese de se colocar a agenda da comunidade como prioridade, a prefeitura como ator com poder de veto pode direcionar o resultado dos conflitos por vetar as propostas encaminhadas pela comunidade. E, complementarmente, pode promover as ações de remoções forçadas.

Com alta estabilidade decisória, se a justiça for acionada, ela terá maior independência para decisão. Mas, embora dentro de um processo legal e legítimo, nem sempre há garantia plena da justiça social e do atendimento às expectativas comuns, sobretudo se esse processo esvaziar o debate político e minimizar o papel dos demais atores (Silva, Comaru, Silva, 2018, pp. 93-94). Nesse caso, para construir uma proposta de permanência da comunidade na área, há que se ter a clareza de que os atores com poder de veto são aqueles cujo consenso é essencial para a mudança do status quo (ibid., p. 392), ou seja, apostar no embate de forças não tende a resultados positivos aos atores que desejam mudanças.

0 ator com poder de veto é aquele que não pode sozinho fazer uma opção diante das alternativas, mas pode vetar alternativas propostas. É assim que ele faz o controle das decisões, sem efetivamente ter uma iniciativa, muito embora o veto não deixa de ser uma decisão. A compreensão do caso aqui tratado é complexa, pois o papel da gestão como ator com poder de veto na verdade se efetiva não porque a gestão não pode decidir, mas porque $o$ veto se faz mais eficiente e articulado com outras ações menos contundentes e de médio prazo, e igualmente eficientes. Compreender o uso da decisão é compreender a institucionalidade que cerca o debate do direito à cidade, 
da provisão de serviços públicos, da regularização fundiária, do desenvolvimento urbano e ambiental. E por quais meios essas decisões passam e, portanto, exigem permanente debate. Nesse caso, o conflito não pode ser confundido com a polarização, mas a resistência deve ser entendida como parte essencial do conflito, pois essa sim representa a construção de espaços democráticos de discussão.

O projeto de urbanização e regularização fundiária como negociação torna-se, assim, elemento central para desatar o impasse, fundamentalmente como instrumento capaz de garantir os direitos da comunidade sem a necessidade de envolver outras instâncias e agentes de decisão para além dos dois atores diretamente envolvidos (comunidade e prefeitura), considerando que a materialização do plano permite deslocar a geometria de poder que está cristalizada em um projeto político e estratégico hegemônico e definido em diferentes escalas. Permite, também, espaço para a gestão discutir a viabilidade de outros projetos de interesse urbano, desde que coletivos. A parcialidade e os interesses da comunidade podem ser garantidos contanto que a proposta seja construída de forma a também atender a requisitos mínimos, mas essenciais, dos atores hegemônicos com poder de veto. Para isso, é fundamental que a proposta apresentada não seja passível de derrotas por alternativas (ibid., p. 98).

A negociação que encontra no projeto uma possibilidade de instrumentalizar o diálogo também pode resultar no argumento racional, técnico e político para a tomada de decisão. Como em casos similares, a aproximação técnica do plano de urbanização e regularização fundiária ao âmbito político da decisão pode construir um novo patamar de debates comprometidos com os interesses coletivos e com a transparência.

\section{Conclusão}

Por um lado, a gestão pública articulada aos financiamentos globais proporciona condições adequadas de reprodução do capital privado, por meio de remoção da população pobre de áreas valorizadas da cidade, apoiada num empreendedorismo urbano que se quer bem-sucedido. Por outro, a resistência da comunidade por meio de propostas e ações planejadoras combativas apoia-se num modelo democrático de cidade, respaldado pelos dispositivos constitucionais, pelos tratados internacionais de direitos humanos e pelas experiências e vitórias das práticas progressistas de desenvolvimento. Os argumentos ambientais são apropriados pela gestão pública na tentativa de substituir a população pobre por obras rodoviaristas contraditórias ao próprio discurso preservacionista. As novas tecnologias e as iniciativas interdisciplinares que levam em conta valores culturais, sociais, urbanísticos, do direito e também os ambientais e econômicos constroem a antítese a esses argumentos. Há, portanto, um projeto de desenvolvimento urbano em conflito que, enquanto estiver baseado numa polarização, pouco colaborará verdadeiramente para um desenvolvimento sustentável.

As novas formas de planejamento, por sua vez, redirecionam o debate e ajuda a evidenciar os conflitos, esses essenciais para a manutenção das decisões democráticas. A resistência que está na base desses conflitos 
ocorre pelas organizações sociais que se concretizam por ações com diferentes origens e que se encontram na conformação de um novo território, ou seja, na conformação de uma disputa de poderes. Esse modo de elaboração de planos e projetos que resulta dessa resistência se vincula às questões políticas com perspectiva emancipatória e busca rearticular - portanto não confrontar - a agenda social em relação à agenda ambiental. 0 que se espera do projeto como síntese da iniciativa popular é que ele como prática esteja fundado no privilégio dos interesses comuns, que direcione as decisões pela regulação do espaço urbano pela prática e pela reflexão como atos políticos de essência democrática, da autogestão e do engajamento pelo bem comum, quebrando os antagonismos que marcam essa discussão.
No conflito interescalar que decorre das evidências acima expostas, entendemos que a negociação ainda seja uma oportunidade de solução. Não a de mediação de conflitos com a qual se verteria para soluções intermediárias e pouco satisfatórias para quaisquer dos lados e até muitas vezes invisibilizadoras das verdadeiras razões dos próprios conflitos, mas negociação como sinônimo de construção de proposta efetiva, pragmática, para contrapor ao discurso e às ações predominantes, ideológicas e unilaterais. Nesse sentido, o papel dos planos e projetos é o de tirar o debate do ambiente ideológico e polarizado pelas ideias hegemônicas e consolidar um desenho concreto da cidade, ou seja, levar a discussão para o âmbito das soluções e não dos discursos para que as decisões sejam tomadas de forma ponderada e coletiva.

\section{[1] https://orcid.org/0000-0003-2482-0380}

Universidade de São Paulo, Instituto de Arquitetura e Urbanismo, Programa de Pós-Graduação em Arquitetura e Urbanismo. São Carlos, SP/Brasil

jctavares@usp.br

\section{[II] https://orcid.org/0000-0003-3069-8019}

Universidade de São Paulo, Instituto de Arquitetura e Urbanismo, Programa de Pós-Graduação em Arquitetura e Urbanismo. São Carlos, SP/Brasil.

mfantin@sc.usp.br

\section{[III] https://orcid.org/0000-0002-3013-7142}

Universidade do Vale do Paraíba, Instituto de Pesquisa e Desenvolvimento, Programa de Pós-Graduação em Planejamento Urbano e Regional. São José dos Campos, SP/Brasil.

douglas.almeida9000@gmail.com 


\section{Referências}

AB'SABER, A. N. (1991). Palestra do professor doutor Aziz Nacib Ab'Saber proferida na Câmara Municipal de São José dos Campos.

ACSELRAD, H.; MELLO, C. C. do A.; BEZERRA, G. das N. (2009). O que é justiça ambiental. Rio de Janeiro, Garamond.

ALBERINI, M. (2015). Parecer técnico socioeconômico: Comunidade Jd. Nova Esperança - Banhado, São José dos Campos. São Paulo, Defensoria Pública do Estado de Paulo/Núcleo Especializado de Habitação e Urbanismo.

ALMEIDA SILVA, D. (2015). Pedido de tombamento da área de proteção ambiental do Banhado de São José dos Campos como patrimônio natural, histórico e paisagístico do estado de São Paulo. São Paulo, Conselho de Defesa do Patrimônio Histórico, Arqueológico, Artístico e Turístico do Estado de São Paulo (Condephaat).

(2017). Banhado Resiste: Estratégias Discursivas de uma Comunidade Habitante de Área Protegida. In: ENANPUR - ENCONTRO NACIONAL DA ASSOCIAÇÃO NACIONAL DE PÓS-GRADUAÇÃO E PESQUISA EM PLANEJAMENTO URBANO E REGIONAL. Anais... ST. 9.2 Ativismo urbano, movimentos sociais e experiências recentes. São Paulo, pp. 1-19.

ALMEIDA SILVA, D.; VIANNA, P. C.; ZANETTI, V. (2017). Urban Planning, Agents and Representations: Creation of the Banhado, São José dos Campos Landmark. Ambiente e Sociedade, v. 20, pp. 163-184.

AMARAL, J. R. (2008). "O voo de São José dos Campos rumo à modernidade". QUEIROZ, A. V. (org.). Com a palavra o prefeito. São José dos Campos-SP, Prefeitura Municipal de São José dos Campos.

ASCHER, F. (2010). Os novos princípios do urbanismo. Tradução e apresentação de Nadia Somekh. São Paulo, Romano Guerra.

BARROS, J.; COSTA, A. D.; RIZEK, C. (orgs.) (2018). Os limites da acumulação, movimentos e resistência nos territórios. São Carlos, IAU/USP.

BID - BANCO INTERAMERICANO DE DESENVOLVIMENTO (2007). Perfil de Proyecto. Programa de Estructuración Urbana - São José dos Campos (PP). Brasil. Disponível em: <http://idbdocs.iadb. org/wsdocs/getdocument.aspx?docnum=1195893>. Acesso em: 6 abr. 2018.

(2011). Contrato de empréstimo n. 2323/OC BR entre o Município de São José dos Campos e o Banco Interamericano de Desenvolvimento/ Programa de Estruturação Urbana. Parte I, II, III. Disponível em: <https://www.iadb.org/pt/project/BR-L1160>. Acesso em: 5 abr 2018.

(2017). Relatório de Verificação e Observância: Programa de Estruturação Urbana de São José dos Campos (BR-L1160) (2323/OC-BR). Disponível em: <http://www.iadb.org/pt/mici/complaintdetail-2014,1804.html?id=BR-MICI006-2011>. Acesso em: 6 abr 2018.

BRASIL (2000). Lei n. 9.985, de 18 de julho de 2000. Regulamenta o art. 225, § 1o, incisos I, II, III e VII da Constituição Federal, institui o Sistema Nacional de Unidades de Conservação da Natureza e dá outras providências. Brasília, Diário Oficial da União, 2000. Disponível em: <http://www.planalto. gov.br/ccivil_03/LEIS/L9985.htm>. Acesso em: 15 mar 2015

COSTA, P. E. O. (2007). Legislação urbanística e crescimento urbano em São José dos Campos. Dissertação de mestrado. São Paulo, Universidade de São Paulo. 
COSTA, S. M. F.; MARIA, M. G. (2010). “Crescimento urbano e novas formas de urbanização na cidade de São José dos Campos”. In: COSTA, S. M. F.; MELLO, L. F. (orgs). Crescimento urbano e industrialização em São José dos Campos - Vol. V. São Paulo, Intergraf.

DEFENSORIA PÚBLICA DO ESTADO DE SÃO PAULO (2014). Defensoria pública informa: toda pessoa tem direito à moradia e de proteção contra remoções forçadas. Informativo. São José dos Campos [panfleto].

EMPLASA-Empresa Paulista de Planejamento MetropolitanoS.A. (2014). Plano de Ação da Macrometrópole Paulista 2013-2040. Disponível em: <https://www.emplasa.sp.gov.br/ Comunicacao/Releases/ Release/PAM-2013-2040-ganha-quatro-publicacoes>. Acesso em: 6 mar 2019.

ESTADO DE SÃO PAULO (2002). Lei 11.262 de 8 de novembro de 2002; Declaram área de proteção ambiental trecho da Serra da Mantiqueira e as áreas urbanas do município de São José dos Campos. Disponível em: http://www.legislacao.sp.gov.br/legislacao/dg280202.nsf/ ae9f9e0701 e533aa032572e6006cf5fd/2c1ec510e6ee69de03256ce600608cd6?OpenDocument. Acesso em: 2 dez 2014.

FERNANDES, M. T. M. (2010). “A segregação mostrando sua força na produção do espaço intraurbano: o deslocamento da classe de alta renda na cidade de São José dos Campos". In: COSTA, S. M. F.; MELLO, L. F. (orgs.). Crescimento urbano e industrialização em São José dos Campos - v. V. São Paulo, Intergraf.

HARVEY, D. (2005). A produção capitalista do espaço. São Paulo, Annablume.

LAVAL, C. (2018). “Os usos intelectual, social e político do comum”. In: BARROS, J.; COSTA, A. D.; RIZEK, C. (orgs.) (2018). Os limites da acumulação, movimentos e resistência nos territórios. São Carlos, IAU/USP, pp. 161-169.

LEAL, V. N. (2012). Coronelismo, enxada e voto: o município e o regime representativo no Brasil. São Paulo, Companhia das Letras.

LENCIONI, S. (2008). Concentração e centralização das atividades urbanas: uma perspectiva multiescalar. Reflexões a partir do caso de São Paulo. Revista de geografia Norte Grande. Santiago, n. 39, pp. 7-20. Disponível em: <https://https://scielo.conicyt.cl/scielo.php?script=sci_arttext\&pid =S0718-34022008000100002. Acesso em: 11 mar 2019.

MATUS, C. (1996a). Adeus, senhor Presidente. Governantes governados. São Paulo, Edições Fundap. (1996b). Estratégias políticas: Chimpanzé, Maquiavel e Gandhi. São Paulo, Edições Fundap.

$\mathrm{MCl}$ - Mecanismo Independente de Consulta e Investigação (2017). Relatório de Verificação e Observância: Programa de Estruturação Urbana de São José dos Campos (BR-L1160) (2323/ $O C-B R$ ). Disponível em: <http://www.iadb.org/pt/mici/complaint-detail-2014,1804.html?id=BRMICI006-2011>. Acesso em: 6 abr 2018.

MORELLI, A. F.; SANTOS, A. P. dos (1996). O Banhado de São José dos Campos. Revista Pós. São Paulo, FAU-USP, número especial 2, pp. 79-85.

OLIVEIRA, F. de (1981). A economia brasileira: crítica à razão dualista. Petrópolis, Vozes.

PORTAL JORGE WILHEIM (2015). Parque do Banhado. Jorge Wilheim - O Legado. Disponível em: http:// www.jorgewilheim.com.br/legado/Projeto/visualizar/1852. Acesso em: 10 out 2015. 
RESCHILIAN, P. R.; SANTOS, C. R. (2014). “Representações socioespaciais de moradores da Favela Nova Tatetuba em São José dos Campos”. In: GUIMARÃES, A. C. M.; ZANETTI, V. (orgs.). São José dos Campos: cotidiano, gênero e representação - Vol. VII. São José dos Campos-SP, Univap.

ROSA FILHO, A. (2002). As políticas públicas do poder executivo municipal na remoção e/ou reurbanização das favelas do município de São José dos Campos. Dissertação de mestrado. São José dos Campos-SP, Universidade do Vale do Paraíba.

SANTOS, C. R. dos (2010). Descortinando o espaço do "Nova Tatetuba" ou "Morro do Regaço" em São José dos Campos (1956-2004). Trabalho de Conclusão de Curso em História. São José dos Campos-SP, Universidade do Vale do Paraíba.

SÃO JOSÉ DOS CAMPOS (1961). Secretaria de Planejamento Urbano. $1^{\circ}$ Plano Diretor de Desenvolvimento Integrado (PDDI)/ Plano Preliminar. PMSJC, Cepeu/FAU-USP.

(1971). Secretaria de Planejamento Urbano. $2^{\circ}$ Plano Diretor de Desenvolvimento Integrado (PDDI) - vol. I. PMSJC, Serete Engenharia S/A.

(1972). Secretaria de Planejamento Urbano. $1^{\circ}$ Plano Diretor de Desenvolvimento Integrado (PDDI)/ Planos Setoriais - vol. I, II. PMSJC, Cepeu/FAU-USP.

(1984). Lei 2792/84 de 10 de janeiro de 1984; Declara área de proteção ambiental a região do Banhado de São José dos Campos. Disponível em: http://www.ceaam.net/sjc/legislacao/ leis/1984/L2792.htm. Acesso em: 2 dez 2014.

(1995). Secretaria de Planejamento Urbano. $3^{\circ}$ Plano Diretor de Desenvolvimento Integrado (PDDI): um plano da cidade para a cidadania. PMSJC, Unesp, Rio Claro-SP.

(1999). Lei n. 5366/99 de 23 de abril de 1999, que autoriza a implantação do "Programa Habitar Brasil/BID" no Município de São José dos Campos. Disponível em: https://leismunicipais.com.br/ pdf/Lei-ordinaria-5366-1999-Sao-jose-dos-campos-SP.pdf. Acesso em: 14 maio 2018.

(2006). Lei complementar n. 306, de 17 de novembro de 2006 que aprova o Plano Diretor de Desenvolvimento Integrado (PDDI). Disponível em: www.camara-municipal-de-sao-jose-doscampos.jusbrasil.com.br. Acesso em: 4 mar 2014.

(2010). Proposta de Criação do Parque Natural Municipal do Banhado. SEMEA - Secretaria de Meio Ambiente/Prefeitura Municipal de São José dos Campos (PMSJC). Consulta Pública, 2010. Disponível em: xa.yimg.com/kq/groups/15951668/.../banhado_consulta_final.pdf. Acesso em: 11 out 2014.

(2012). Lei 8756 de 28 de dezembro 2012, cria o Parque Natural Municipal do Banhado PNMB - e dá outras providências. Disponível em: https://www.leismunicipais.com.br/a/sp/s/ sao-jose-dos-campos/lei-ordinaria/2012/875/8756/lei-ordinaria-n-8756-2012-cria-o-parquenatural-municipal-do-banhado-pnmb-e-da-outras-providencias-2012-06-28.html. Acesso em: 5 mar 2014.

(2013). EIA/RIMA - Estudo de Impacto Ambiental/Relatório de Impacto Ambiental. Planservi/ Cobrape. Vol. I. São Paulo, Semea - Secretaria de Meio Ambiente do Município de São José dos Campos. Disponível em: http://servicos2.sjc.sp.gov.br/media/536013/eia_volume_i. compressed.pdf. Acesso em: 10 mar 2019. 
SÃO JOSÉ DOS CAMPOS (2015). Lei municipal n. 9.258, 5 de maio de 2015, institui o Programa Municipal de Compra Assistida e dá outras providências. Disponível em: https://leismunicipais.com.br/ a2/sp/s/sao-jose-dos-campos/lei-ordinaria/2015/925/9258/lei-ordinaria-n-9258-2015-instituio-programa-municipal-de-compra-assistida-e-da-outras-providencias. Acesso em: 10 fev 2019.

SILVA, E. A. da; COMARU, F. de A.; SILVA, S. J. da (2018). Direito à moradia e judicialização: atuação da Defensoria Pública Paulista. Revista Estudos de Sociologia, v. 23, n. 45. Araraquara, Unesp.

SOUZA, A. A. M.; COSTA, W. M. (2010). "Atividades industriais no interior do Estado de São Paulo: uma análise da formação do complexo tecnológico-industrial-aeroespacial de São José dos Campos". In: COSTA, S. M. F.; MELLO, L. F. (orgs.). Crescimento urbano e industrialização em São José dos Campos - Vol. V. São Paulo, Intergraf.

SOUZA, J. S. de (2015). O papel da Defensoria Pública no controle das políticas públicas relacionadas aos Direitos Fundamentais Sociais à Cidade e à Moradia Digna: o caso BID-HABITAR Brasil, São José dos Campos, São Paulo. Dissertação de mestrado. Lorena-SP, Centro Universitário Salesiano de São Paulo.

(2018). "O Caso Pinheirinho: sobre o direito insurgente e a resistência no território". In: BARROS, J.; COSTA, A. D.; RIZEK, C. (orgs.). Os limites da acumulação, movimentos e resistência nos territórios. São Carlos, IAU/USP, pp. 121-137.

TSEBELIS, G. (2009). Atores com poder de veto: como funcionam as instituições políticas. Rio de Janeiro, Editora FGV.

VILLAÇA, F. (2001). Espaço intra-urbano no Brasil. São Paulo, Studio Nobel, Fapesp, Lincoln Institute.

Texto recebido em 11/mar/2019

Texto aprovado em $27 / \mathrm{jul} / 2019$ 